and tends to be strictured, at last gets to be retention cyst.

Because the opening part of the duct were surrounded with lymphoid tissue, easily should become to be strictured.

Therefor epiglottic cysts are divided into three classes as follows, (Fig. 4-6)

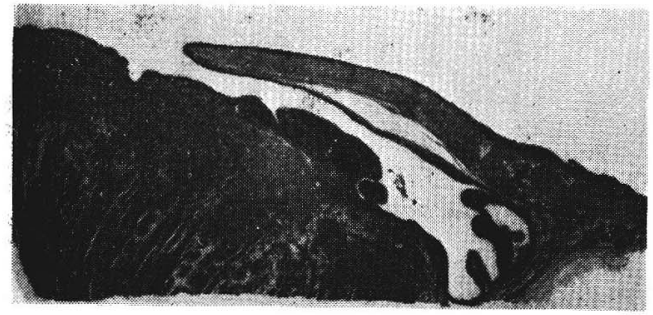

Fig. 4, Cyst on opening part of duct

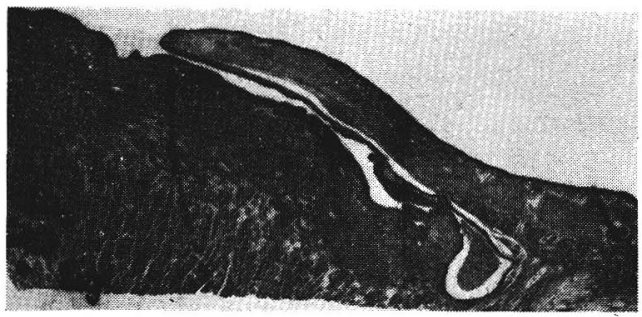

Fig. 5, Ductal cyst

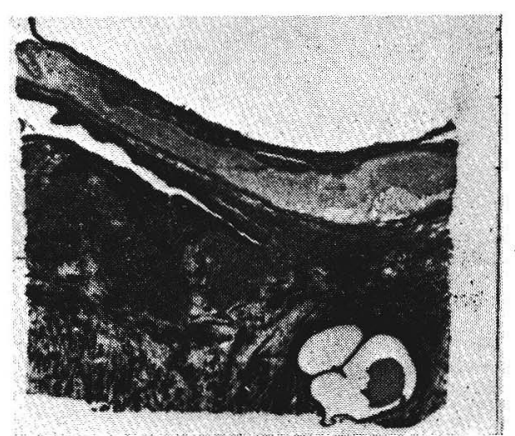

Fig. 6, cyst of gland

(1) cysts on the opening part of duct,

(2) ductal cysts,

(3) cysts of gland.

From olden times, for the purpose of investigating the origin of the formation of epiglottic cysts, internal epithel of cyst, surrounding tissue (lymphoid tissue, gland etc.) and the fact that cyst is divided with septum or not, have been discussed. But those factors would be settled easily, if think about the above mentioned three cases. Cyst on the opening part is covered with stratified squomous epithel and surrounded with lymphoid tissue. Ductal cyst may be covered with various forma! epithel. Glandular cyst happens frequently at transitional part of epiglottis and lingual ground, and is divided by septum. But because the epithel tends to change, the origin of formation is don't researched with it only.

\title{
Histological Investigation of Oesophagitis Oedematosa Circumscripta Chronica
}

* Shoji Niho M. D.

Kazuhide Yasuda M. D.

In 1951, a lesion which should be referred to as Oesophagitis Oedematosa Circmscripta Chronica was presented by the authors. The chief complaint of patients with this lesion is foreign-body sensation at the upper part of the oesophagus. Although there are many

* Yokohama Kyoyu-Kai 
気食会報一 10 巻

diseases with produce a similar sensation, this lesion may be considered as the predominant chief cause of it.

During the past 10 years, the authores have been carrying out a histopathological study of specimens removed endoscopically in cases with this lesion and findings observed in. 91 cases are as follows :

1. Sex Male $\quad 37$

2. Age $0-20 \quad 2$

$21-30 \quad 10$

$31-40 \quad 22$

$41-50 \quad 23$

$51-60 \quad 21$

$61-\quad 10$

3. Epithelium Hypertrophy or thickness

$\begin{array}{lr}\text { Uncertain } & 3 \\ \text { Hypertrophy or thickness } & 54\end{array}$

No change $\quad 36$.

Atrophy 1

4. Edema in the submucous layer $\quad$ W 34

\# 32

$+19$

$-6$

5. Dilatation of capillaries in the submucous layer $\quad$ Ht 27

H. 33

$+25$

$-6$

6. Congestion of capillaries $\quad$ Ht 22

\# 20

$+20$

$-29$

7. Hemorrhage in the submucous layer $\quad$ Hi 2

+ 3

$+8$

$-78$

8. Cell infiltration in the submucous layer $\quad$ Ht 2

+ 12

$+63$

$-14$

9. Other changes in the submucous layer

Fibrosis

$\begin{array}{ll}\text { Stasis in the capillaries } & 15\end{array}$

Organization

$$
64-64
$$


Varix like change

Fibrinoid swelling of capillaries

$$
\begin{array}{rr} 
& 1 \\
\text { W } & 15 \\
+ & 11 \\
+ & 26 \\
-\quad 39 \\
& 3 \\
\text { W } & 6 \\
+ & 5 \\
+ & 11 \\
- & 69
\end{array}
$$

Degeneration of the muscular tissue

Esophagoscopically in this lesion, edema, swelling and sometimes redness of the mucous membrane are observed at the part $17-22 \mathrm{~cm}$ in distance from the upper incisor teeth. Specimen for biofsy were taken for histological examination.

The initial sign of histopathological change observed is congestion of capillaries in the submucous layer of the oesophagus. Then as a result of increased permeability of the capillaries serous transudate, sometimes red cells (hemorrhagia per diapedesin) and cell infiltration around the capillaries are seen. Moreover, the loose submucous layer becomes diffusely edematous.

In cases where the above mentioned changes have been persistingly present, the epithelial layer is hypertrophied or thickend, and edema develops in the tunica muscularis mucosae. Capillaries are dilated moderately, showing stasis at times and although infrequently even varix like figurations. In some cases there are hemorrhage and organization of blood in the submucous layer. When edema in the submucous layer is marked and present continuonsly for a long time, fibrin appears in the edematous region. In some special cases, proliferation of glandular tissue and dilatation of ducts are found.

It is however, apparent that subjective symptoms produced by this lesion arise from two sources, i. e. the above recorded organic histopathological changes and emotional elements.

The chief complaints of patients with this lesion are foreign-body sensation in the throat, esophagus or neck, stiffness of shoulder, obstructed feeling in the throat or esophagus, oppressive feeling in the chest and expectoration of blood etc.

When these subjective symptoms persist for a long period patients will tend to worry about the presence of ascaris in the esophagus lumen, laryngeal tuberculosis or cancer of the larynx or eso hagus. Especially when these patients meet or thear of individuals suffering from cancer of the larynx or esophagus they will become terror stricken. On the other hand, in the majority of those patients who exhibit strong emotional disturbances traits of neurotic, hysteric or schizophrenic tendency are observable.

\section{Summary}

1. A statistical investigation of oesophagitis circumscripta oedematosa chronica in 91 patients is present. 


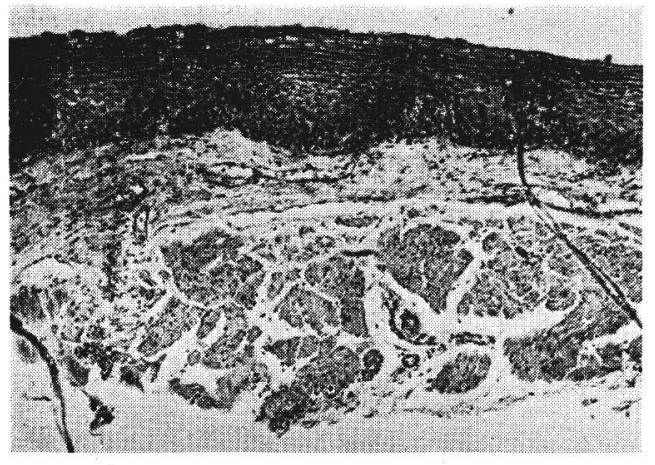

Fig. 1. Normal oesophagus. Changes appear in the submucous layer.

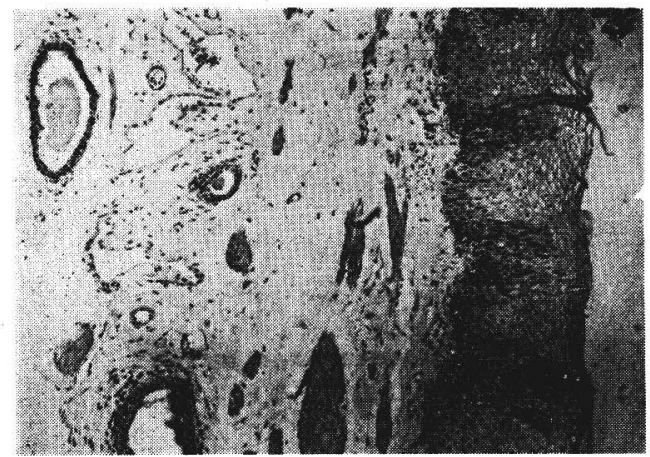

Fig. 3. Edema. Cell infiltration, Haemorrhagia per diapedesin. Dilatation of ducts.

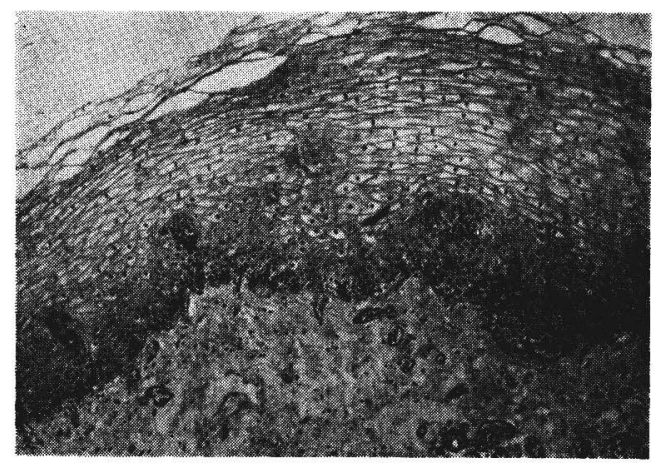

Fig. 5. Thickness of epithelium. Cell infiltration. Dilatation of capillalies. Congestion, Edema.

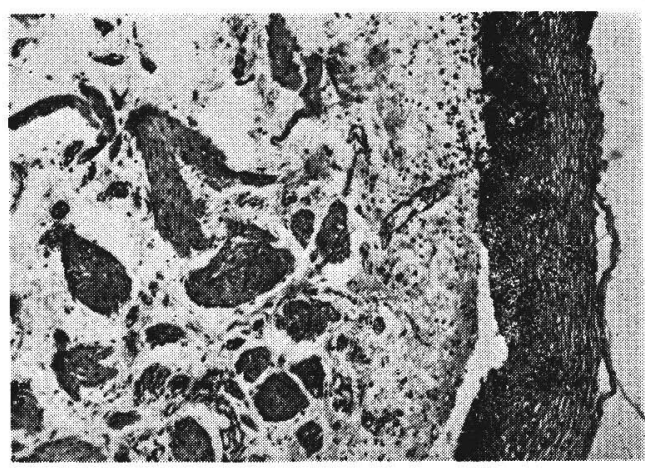

Fig. 2. Cell infiltration in the propria. Edema. Appearance of fibrin. Edema in the muscularis mucosae.

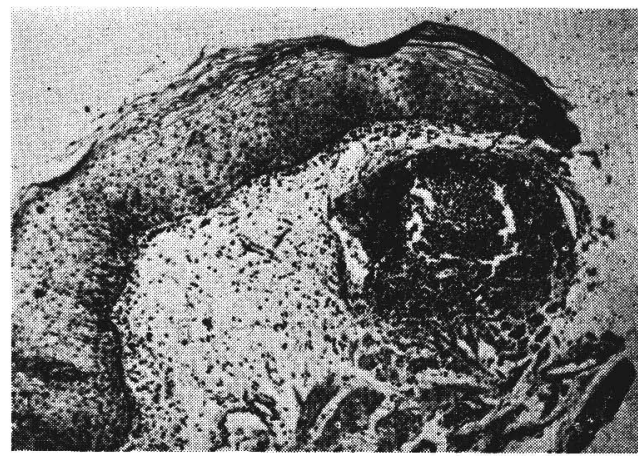

Fig. 4. Cell infiltration. Dilatation of lymph vessels. edema. Appearance of fibrin. Lymph follicle.

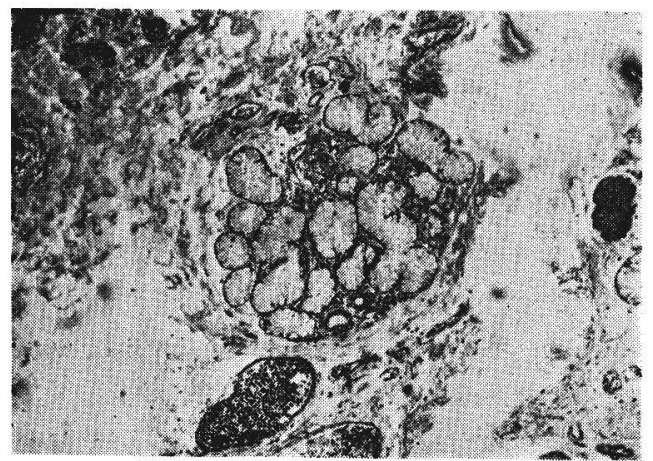

Fig. 6. Proliferation of glandular Tissue. Edema. Appearance of fibrin. 


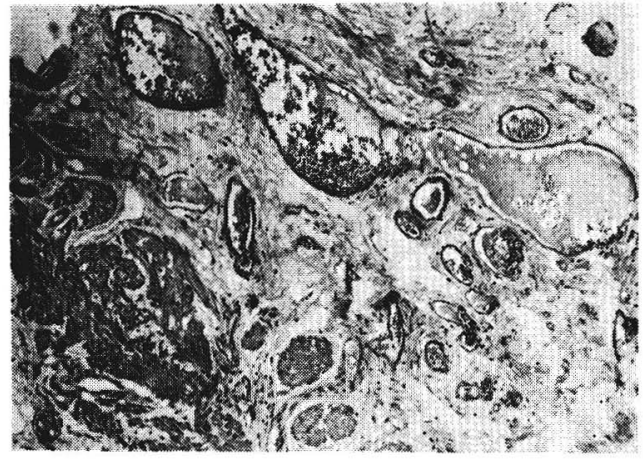

Fig. 7. Edema in the muscularis mucosae. Appearance of fibrin. Congestion. Stasis.

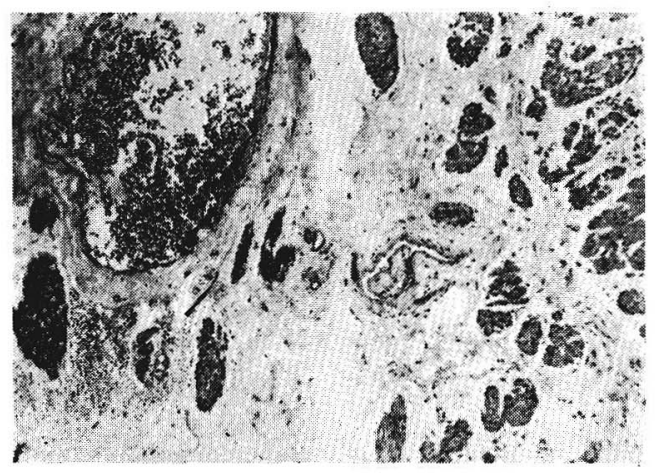

Fig. 9. Dilatation of blood vessels. Congestion. Edema. Haemorrhage.

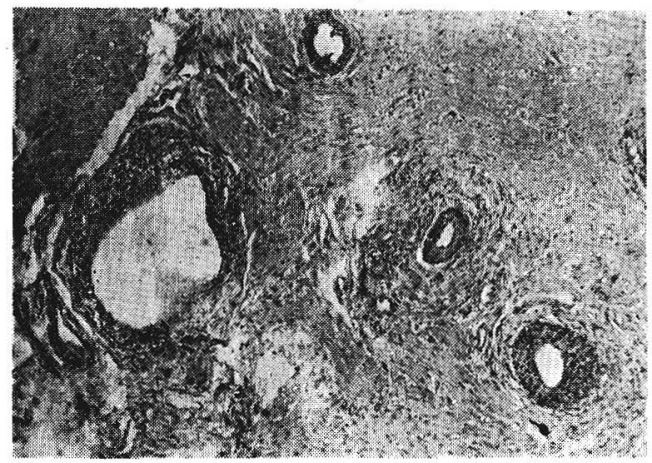

Fig. 11. Dilatation of ducts. Organization.

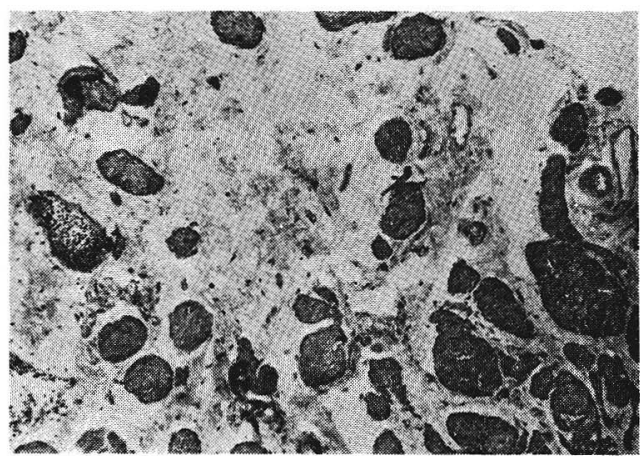

Fig. 8. Edema in the Muscularis Mucosae. Appearance of fibrin.

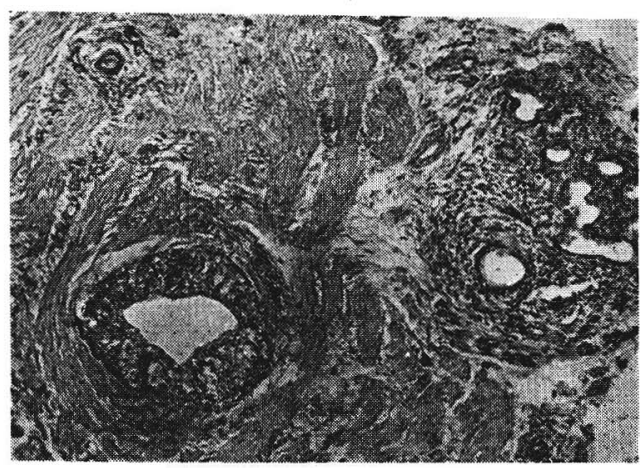

Fig. 10. Dilatation of ducts. Organization.

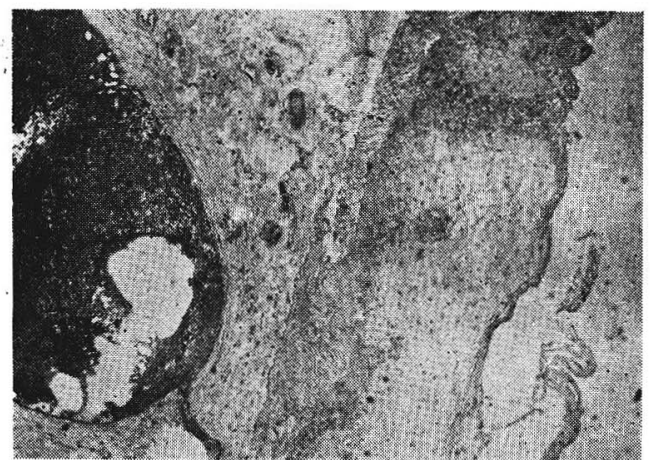

Fig. 12. Proliferation of epithelium. Congestion. Haemorrhage. Organization. 
2. As an initial sign of this lesion, congestion or hyperemia of capillaries in submucous layer of the esophagus is histologically observed. Following increased permeability of capillaries serous transudate appears and then edema, hemorrhagia per diapedesin or rhexin and cell infiltration take place.

In the second stage fibrin appears in the edematous, region, and sometimes organization process, varix like formation or change of glandular ducts are demonstrated.

3. Not only these histopathological changes but also the characteristic tendency of patients to worry about cancer, tuberculosis or ascaris in the laryngo-esophageal region are of impotance in the concept of this lesion, as those people with extreme traits of neurosis are liable to manifest severe subjective symptoms.

\section{Refarences}

(1) S. Niho, K. Yoshio, S. Inaba: The Journal of the Japan Broncho-Esophagological Society ; Vol. 2, No. 1, P. 6.1951.

(2) K. Yoshio : Otolaryngology Tokyo: Vol.22, No. 5, P. 215. 1950.

(3) S. Inaba : Otolaryngology Tokyo: Vol. 22, No. 7, P. 309. 1950.

(4) N. Takahata : Yokohama Medical Journal ; Vol. 3, No. 1-2, P. 1. 1952.

(5) S. Niho, T. Iwatake, N. Takahata : The Journal of the Japan

Broncho-Esophagological Society ; Vol. 5, No. 1, P. 18. 1954.

\section{Histological Studies on the Nervous System of the Lung}

* by Nobuo Inaba

I wish to report on a few findings I made while taking histological studies on the structure of the nervous system of the lung since 1954 .

The lungs of men and dogs were used as materials of my studies and Suzuki's modification of Bielschowsky's silver impregnation and Sugamo's staining method of myelin sheath were chiefly employed as staining method of the nerve as shown in Slide No. 1.

As is well known, nerve control of the lung is performed by sympathetic, vagal and phrenic nerve, the nerve fibers of which from anterior and posterior pulmonary plexus at the root of the lung. The nerve fibers from the plexus are distributed to the lung accompanying the bronchi and pulmonary vessels as shown in Slide No. 2. Numerous nerve fibers are also distributed to the pulmonary pleura forming a nerve network as shown in Slide No. 3. The bundles of nerve fibers that run along the bronchi are rel-

* Surgical Division of the Tuberculosis Research Institute, Kyoto University

$$
68-68
$$

